\title{
Describing behavior in small groups with the Datamyte event recorder
}

\author{
RAND D. CONGER and DOUG MCLEOD \\ University of Georgia, Athens, Georgia 30602
}

\begin{abstract}
A technology for coding and analyzing behavior in human groups is described. The behavior code is based on the scoring of verbal and physical contacts, emotional affect, and commands and complies. The code is reasonably valid and produces sufficiently high levels of observer agreement. Currently available computer programs for analyzing frequencies, rates, and proportions of behavior, as well as equity and reciprocity in behavioral transactions, are discussed. The development of programs for analyzing more microscopic features of interaction is also noted.
\end{abstract}

With increasing frequency, the wisdom of studying social behavior in settings that are almost always contrived is being questioned (Barker, 1968; Blurton-Jones, 1972; Johnson, Wahl, Martin, \& Johansson, 1974). But the study and recording of behaviors in natural settings is not a simple task. Generally, the researcher must have a system for rapidly coding and storing observed activities. Most often this requires portable equipment that can be used relatively unobtrusively in the field. And, the data obtained must be amenable to analyses which will help to expose regularities or functional relationships in the interactions of the people involved. To achieve this end, the original coding of behaviors should be easily transferable to a computer, so that a permanent interaction record may be used for various types of data reduction. In turn, any apparent regularities in the data that are identified become the stuff by which propositions amenable to experimental test are generated (Blurton-Jones, 1972; Patterson, 1976).

The Datamyte 900 event recorder incorporates the features necessary to meet the needs of this data collection approach. The unit is portable, links directly with the computer, and records behaviors in sequence. Recording events sequentially, along with the automatic recording of the time of each event, allows for the analysis and description of regularities in the data suggestive of causal relationships. These features of the Datamyte system, then, are consistent with our attempt to wed some of the substantive issues typical to social psychology with an ethological approach to research methods.

\section{THE BEHAVIOR CODE}

Since social interaction is our research focus, the

Reprints may be obtained by writing Rand Conger, Department of Sociology, Baldwin Hall, University of Georgia, Athens, Georgia 30602. behavior code is specifically tailored to describe behaviors exchanged between individuals. Rather than list all possible events in catalog fashion, the decision was made to build a code based on a dichotomy between verbal and physical behavior. ${ }^{1}$ During coding, an observer follows the activities in a particular group. $\mathrm{He}$ or she focuses on a particular person for a set time period and then, on signal from the Datamyte, switches to the next focal subject.

As illustrated in Table 1, the first distinction an observer must make is whether the focal subject communicates with another group member either verbally (verbal give/receive) or physically (physical give/receive). After entering the number for the type of interaction via the Datamyte keyboard, the coder then moves to the second column and enters the emotional affect of the behavior $(1=$ neutral, 2 = positive, $3=$ negative). Next, the person interacting with the focal subject is entered in Columns 3 and 4 . To complete the five-column field, the observer notes whether the behavior involved is (1) a prescriptive command ("do this"), (2) a proscriptive command ("don't do that"), (3) a comply, (4) a refusal, or (5) none of these.

Table 2 illustrates the information transmitted to the computer after a group has been observed. The table shows that the Datamyte recorder automatically accounts for the passage of time as observation proceeds. It also supplies a line number for each entry for easier editing. Each observer records only the five columns of interaction data. For example, in Table 2 the first entry indicates that the researchers are concentrating on focal Subject 1 and his/her interactions with every other person in the group. Within $.3 \mathrm{~min}$ (Column 3 , Line 2), focal speaks (Column 2, Digit 1), in a neutral fashion (Second 1), to Subject 2 (code 02); the verbalization is neither a command nor a comply (code 5, the last digit). At $.7 \mathrm{~min}$ into the session, Subject 2 responds in kind. At $1.1 \mathrm{~min}$, Subject 1 interacts physically with Subject 2 in a negative fashion, 
Table 1

The Behavior Code

\begin{tabular}{|c|c|c|c|}
\hline $\begin{array}{c}\text { Type of Interaction } \\
\text { Column } 1\end{array}$ & $\begin{array}{c}\text { Emotional Affect } \\
\text { Column } 2 \\
\end{array}$ & $\begin{array}{c}\text { Other Actor } \\
\text { Columns } 3 \text { and } 4 \\
\end{array}$ & $\begin{array}{l}\text { Commands/Complies } \\
\text { Column } 5\end{array}$ \\
\hline $\begin{array}{l}\text { Verbal Give }=1 \\
\text { Verbal Receive }=2\end{array}$ & $\begin{array}{l}\text { Neutral }=1 \\
\text { Positive }=2\end{array}$ & Group Member 1 = 01 & $\begin{array}{l}\text { Prescriptive Command }=1 \\
\text { Proscriptive Command }=2 \\
\text { Comply }=3\end{array}$ \\
\hline $\begin{array}{l}\text { Phy sical Give }=3 \\
\text { Physical Receive }=4\end{array}$ & Negative $=3$ & Last Group Member $=\mathbf{n}$ & $\begin{array}{l}\text { Refuse }=4 \\
\text { None of these }=5\end{array}$ \\
\hline
\end{tabular}

usually a hit. Subject 2 then responds in kind. At $1.5 \mathrm{~min}$, Subject 1 delivers a verbal positive to Subject 2 , which is reciprocated at $2 \mathrm{~min}$, with the two combatants having settled their differences. A row of nines is entered to begin a new focal and a row of sevens follows the nines when a session ends.

In comparing this particular coding scheme to others, several issues must be addressed. First, is the code objective; that is, does it require little subjective judgment on the part of observers? For the most part, the criterion of objectivity is met. Observers experience very little difficulty in identifying verbal and physical interactions after only minimal training, 2-4 weeks (Conger, 1976). Even the command and comply categories are straightforward. However, while most aspects of the code produce observer agreement coefficients well above .90 , the affect categories are a problem. Only if the Spearman-Brown correction is used to compensate for the fact that agreement scores are not computed for all observations are the agreement figures for affect above .80 (Conger, 1976; see Johnson $\&$ Bolstad, 1973, for a discussion of the correction formula). On the other hand, even the affect codes are becoming more reliable as we continue to refine our definitions.

Another important question concerns the validity of the code. It is possible that the broad categories of behavior which characterize the code produce findings that are not comparable to those involving more detailed descriptions. Fortunately, researchers using "catalog" coding have lumped many behaviors together in order to obtain behavioral frequencies large enough for analysis. For example, Patterson $(1974,1976)$ collapses behavioral categories in order to derive rates of social aggression, hostility, and total deviance. Patterson (1976) reports that children in a treatment program designed to reduce aggressiveness averaged .70 deviant, or aversive, behaviors per minute during baseline observations. The code reported here indicates that, in a sample of child abusing families in Pennsylvania, the children emitted a combination of verbal and physical negatives at a rate of .66 per minute. After intervention, the children in Patterson's sample averaged .41 deviant responses per minute; the control children in the Pennsylvania study averaged .49 negative behaviors per minute (Burgess \& Conger, Note 1).

Thus, the rate of child deviance in Patteron's (1976) clinical sample is quite similar to the rate of negative behaviors by children for our disturbed group. After treatment, the rate of child deviance in his clinical population is comparable to the rate of negatives by our control children. Assuming for the moment that these families are comparable, the similarity in results apparently occurs because almost all of the individual items in Patterson's code for noxious behaviors (1976, p. 272) are encompassed within a category of "total negatives." For example, Patterson's categories "tease" and "humiliate" are verbal negatives in our system. Using Patterson's findings as a criterion, then, it appears that the code has some consensual validity.

Another important test of validity concerns the degree to which a measure varies with other factors in a meaningful or theoretically important way. Here, too, the code seems to function well. In a study of child abuse and neglect (with control families), the code discriminated between family types in the expected directions, even though observers were blind to the type of family observed on any given occasion (Conger, 1976). Observers in this study learned the code most quickly by viewing practice families in the home. A combination of in situ experience along with extended observation and discussion of videotaped groups produced high levels of observer agreement and minimal recording bias as a function of family type.

In sum, the observation code seems to operate well as a measurement tool. It is learned quickly by observers, there is evidence that it produces results similar to other coding procedures, and the results it

Table 2

Interaction Coding

\begin{tabular}{ccc}
\hline Line Number & Interaction & Time \\
\hline 00050 & 1 & 00000 \\
00100 & 11025 & 00030 \\
00150 & 21025 & 00070 \\
00200 & 33025 & 00110 \\
00250 & 43025 & 00120 \\
00300 & 12025 & 00150 \\
00350 & 22025 & 00200 \\
00400 & 99999 & 00250 \\
00450 & 4 & 00300 \\
$\vdots$ & $\vdots$ & $\vdots$ \\
$\vdots$ & etc. & \\
$\mathrm{n}-1$ & $\vdots$ & $\vdots$ \\
$\mathrm{n}$ & 99999 & $\mathrm{t}-1$ \\
\hline
\end{tabular}


produces relate to other variables in a meaningful way. We continue, however, to amend particular features of the observation categories in order to increase observer agreement and the scope of behaviors they encompass.

Combining this particular code with the Datamyte, which records behavior in real time, has distinct advantages over some other approaches. In the work reported by Johnson and Lobitz (1974) and by Patterson $(1974,1976)$, observers code behaviors within family groups using a predetermined set of intervals, usually five within each $30-\mathrm{sec}$ period. This method works fairly well when only rates or frequencies of behavior are considered, but it has disadvantages that are remedied by the Datamyte's real-time recording ability. To illustrate, if sequential dependencies are of interest, for example, the influence of antecedent events on target behaviors, many antecedent intervals that contain more than one behavior will have to be dropped from the analysis using the interval sampling procedure (Patterson, 1976). This problem occurs since there is no way of knowing which of the two or more behaviors in the preceding interval occurred last, that is, the immediate antecedent of the target response.

Thus, the time-sampling method restricts the researcher unduly by forcing him or her to consider as antecedent only those events which occur alone in the last interval, whatever its length. Given that many interesting target behaviors (e.g., physical aggression) occur at low rates, some important analyses may be barred when a number of preceding intervals must be omitted from analysis. Since the Datamyte codes in real time, the data produced are not bound to specific time periods. Indeed, the researcher can consider any immediately preceding event for a target behavior even if the antecedent has one or two behaviors occurring brief seconds before. And, analyses can relate a target response to behaviors separated from it by other interactions (Sackett, Note 2). Since observers can be trained to code behaviors at a rate of one five-digit entry in less than $2 \mathrm{sec}$ on the Datamyte, this concern with rapidly occurring sequences of behavior (as might occur during an argument involving several individuals) has practical significance for Datamyte users.

\section{COMPUTER ACCESS}

Transmitting from the Datamyte to the computer is straightforward (Torgerson, 1977). We interface the Datamyte to a Texas Instruments Model 733-ASR terminal with an EIA RS232C connector. Data are transmitted at 300 baud from the Datamyte to one of two cassette tapes on the T1733. While this is taking place, the data are also listed via the terminal printer. The original observer uses this listing in order to note any errors in the data. Common mistakes in coding include: punching the same number twice so that field length is one digit too large; invalidly showing the focal subject interacting with himself, or failing to add a row of nines with a change in focal subject; or, failing to input a row of sevens to indicate the end of an observation session. While these errors occur infrequently, many other errors are also detected at this time. With the coding errors and needed corrections noted on the initial output, off-line editing is done at the terminal using either in-place or tape-to-tape procedures available via the TI's keyboard, playback, and record controllers. This edited information is transmitted from the cassette to the University of Georgia Computer Center for permanent storage and analysis. Later transformations of the raw data also provide checks on coding errors.

The TI terminal is connected to the University System Computer via switched line (telephone and acoustic coupler). Data processing is accomplished on a Control Data Corporation (CDC) CYBER 70, Model 74, using the Network Operating System (NOS) timesharing capabilities. This unit is interconnected with two IBM 370 Model 158 computers, each of which, along with the CDC, has three megabytes of memory. Once the raw data are stored within the CDC, a series of programs, described below, transform the data into a more usable format and then provide the desired analyses.

\section{DATA ANALYSIS}

\section{Transformations}

Two interactive processing programs, written in BASIC, are used to transform the raw data. Interprogram communication is achieved using NOS files. The first program defines the legitimate parameters of the data to be analyzed including variable locations and ranges. It also reformats the data for initial analysis. Currently, behavioral data up to five digits in length can be processed as shown in Table 2. With a few simple commands, the operator can define as legitimate codes varying from this maximum of five entries to as few as two. Thus, the system allows for some flexibility according to the interests of the researcher. Moreover, the exact behaviors to be analyzed can differ from the present code as long as they are clearly defined within the first stage of data transformation. For example, the first two digits of our current code can be used to catalog a list of up to 99 specific behaviors, while Columns 3 and 4 continue to indicate the other interactor besides the focal subject. Column 5 , then, can be taken out entirely, leaving a four-digit entry.

After the parameters of the raw data are defined, the first program checks for errors and makes any anomalies known to the user. When errors are flagged, editing can be done using the NOS Text Editor or other interactive commands. Once the raw data are appropriately described and errors are corrected, the 
Table 3

Initial Data Transformations

\begin{tabular}{|c|c|c|c|c|c|c|c|}
\hline $\begin{array}{c}\text { Session Number } \\
1\end{array}$ & $\begin{array}{l}\text { GR Number } \\
\quad 2\end{array}$ & $\begin{array}{l}\text { Month } \\
4\end{array}$ & $\begin{array}{c}\text { Day } \\
4\end{array}$ & $\begin{array}{l}\text { Year } \\
7\end{array}$ & $\begin{array}{l}\text { Patamyte Number } \\
1\end{array}$ & $\begin{array}{l}\text { Observer Numbe } \\
1\end{array}$ & $\begin{array}{l}\text { Number of Focals } \\
4\end{array}$ \\
\hline \multicolumn{2}{|c|}{$\begin{array}{l}\text { Focal Number } \\
4 \\
\end{array}$} & \multicolumn{2}{|c|}{$\begin{array}{l}\text { Total Time as Focal } \\
590\end{array}$} & \multicolumn{4}{|c|}{$\begin{array}{c}\text { Number of TRG2 (Interaction Records for Focal)* } \\
9\end{array}$} \\
\hline & & $\begin{array}{l}\text { Type of } \\
\text { Behavior }\end{array}$ & Affect & $\begin{array}{l}\text { Other } \\
\text { Person }\end{array}$ & Command & & $\begin{array}{c}\text { Time Elapsed } \\
\text { Since Last } \\
\text { Entry for } \\
\text { This Focal }\end{array}$ \\
\hline \multirow{2}{*}{\multicolumn{2}{|c|}{ (Interaction 1) }} & $\begin{array}{l}4 \\
2 \\
2\end{array}$ & $\begin{array}{l}1 \\
1 \\
1\end{array}$ & $\begin{array}{l}2 \\
2 \\
1\end{array}$ & $\begin{array}{l}5 \\
5 \\
5\end{array}$ & $\begin{array}{l}0 \\
0 \\
0\end{array}$ & $\begin{array}{l}22 \\
26 \\
22\end{array}$ \\
\hline & & $\vdots$ & $\vdots$ & $\vdots$ & $\vdots$ & $\vdots$ & $\vdots$ \\
\hline \multicolumn{2}{|c|}{ (Interaction 9) } & 2 & 1 & 1 & 5 & 0 & 05 \\
\hline
\end{tabular}

*TRG 2 records are interaction entries. Thus, Focal Number 4 will show a total of nine interactions.

second transformation program provides appropriate labels for the variables of interest. Together, these two programs build a relatively rigid, hierarchical file based on three dimensions: (1) the identity of the particular observation session and group; (2) the specific observer(s) involved; and (3) the interactions recorded. Table 3 illustrates the form in which the data is stored after being revised by the first two processing programs. At this stage, the data are ready for the first in a series of analytic programs.

The first line in Table 3 comes from a set of pretrial information entered in the Datamyte previous to the interaction data shown in Table 2. The pretrial entries describe the session number from which the coded interactions come, the particular group involved, the date of observation, the specific Datamyte used, who observed, and the total number of focal subjects involved. Next, for each focal subject, total time as focal is shown (in this instance, $5.90 \mathrm{~min}$ ), along with the number of interactions recorded for this focal. Finally, each interaction for every focal is enumerated along with the elapsed time between behavior entries. This data format is used for the first stage in data analysis.

\section{Frequencies and Rates of Behavior}

All the analytic programs are written in BASIC. The first of these provides a descriptive summary of the data, as illustrated in Table 4. The ouput displayed is a simulation of that obtained from a three-person group. The behavior described in the table can be any of the logical possibilities from the code (e.g., all negative physicals or all positives, both physical and verbal). Every combination that the code produces may be analyzed according to the format shown in Table 4.

Prior to the output contained in Table 4, the program prints a matrix showing time as focal for each group member as well as identifying information such as group number, date of observation, and observer number.
Printouts may be obtained at the terminal, or a program option automatically switches output to a central printer. Above each series of matrices like the ones found in Table 4 is a behavior label (e.g., verbal gives and receives).

Assuming that the figures in Table 4 represent verbal behavior, they indicate how frequently one group member talks to another, the rate of these responses, and the proportional allocation of verbalizations within dyads and for the group as a whole. Column 1 represents the verbal behavior of the first group member; the zero

Table 4

Description of the Interaction Data

\begin{tabular}{|c|c|c|c|}
\hline 1 & 2 & 3 & 23 \\
\hline \multicolumn{4}{|c|}{1 Person 1} \\
\hline $\begin{array}{l}0 \\
.00 \\
.00 \\
.00 \\
.00\end{array}$ & $\begin{array}{r}20 \\
2.00 \\
66.67 \\
50.00 \\
20.00\end{array}$ & $\begin{array}{l}10 \\
1.00 \\
33.33 \\
33.33 \\
10.00\end{array}$ & $\begin{array}{l}30 \dagger \\
3.00 \dagger \dagger \\
100.00 * \\
30.00 * * \\
30.00 * * *\end{array}$ \\
\hline \multicolumn{4}{|c|}{2 Person 2} \\
\hline $\begin{array}{l}10 \\
1.00 \\
33.33 \\
33.33 \\
10.00\end{array}$ & $\begin{array}{l}0 \\
.00 \\
.00 \\
.00 \\
.00\end{array}$ & $\begin{array}{l}20 \\
2.00 \\
66.67 \\
66.67 \\
20.00\end{array}$ & $\begin{array}{r}30 \\
3.00 \\
100.00 \\
30.00 \\
30.00\end{array}$ \\
\hline \multicolumn{4}{|c|}{3 Person 3} \\
\hline $\begin{array}{r}20 \\
2.00 \\
50.00 \\
66.67 \\
20.00\end{array}$ & $\begin{array}{l}20 \\
2.00 \\
50.00 \\
50.00 \\
20.00\end{array}$ & $\begin{array}{l}0 \\
.00 \\
.00 \\
.00 \\
.00\end{array}$ & $\begin{array}{r}40 \\
4.00 \\
100.00 \\
20.00 \\
40.00\end{array}$ \\
\hline \multicolumn{4}{|l|}{23 Total } \\
\hline $\begin{array}{r}30 \\
3.00 \\
30.00 \\
100.00 \\
30.00 \\
\end{array}$ & $\begin{array}{r}40 \\
4.00 \\
40.00 \\
100.00 \\
40.00 \\
\end{array}$ & $\begin{array}{r}30 \\
3.00 \\
30.00 \\
100.00 \\
30.00 \\
\end{array}$ & $\begin{array}{l}100 \dagger \\
10.00 \dagger \dagger \\
100.00^{* * *} \\
100.00 \\
100.00\end{array}$ \\
\hline
\end{tabular}


entries show that the first subject cannot speak to him/herself. That is, the " 1 Person 1" entered in the left margin represents the first recipient of verbalizations to be considered in the matrix of interactors.

Moving down the rows, when "2 Person 2" appears, the first entry shows that Subject 1 spoke to Subject 2 10 times in this session. The next figure transforms the frequency to a rate of one verbalization per minute. ${ }^{2}$ After this rate, the next row indicates that Subject 1's verbalizations account for $33.33 \%$ of all speaking directed to Subject 2 . The next entry shows that Subject 1 directed $33.33 \%$ of all his/her verbalizations to Subject 2 (10 out of 30 ). Finally, the last row for Subject 1 indicates that the number of times Subject 1 spoke to Subject 2 accounts for $10 \%$ of all talking for this session ( 10 verbalizations out of 100 ).

Moving down Column 1, the figures showing behavior directed by Subject 1 to Subject 3 can be interpreted in the same way. Not included here is the next section in the output (labeled 21), which would show how many times Subject 1 spoke to the group as a whole. Finally, under the heading " 23 Total," Subject 1 spoke 30 times in this session, for an overall rate of 3 times per minute. These behaviors account for $30 \%$ of all speaking in the group, and for $100 \%$ of all of Subject 1's verbalizations. The final row is redundant with the row two steps before it.

Columns 2 and 3 represent Subjects 2 and 3 and are interpreted in the same fashion as Column 1. Column 23 provides row totals and percentages. For example, the first entry shows that Subject 1 was spoken to a total of 30 times for a rate of 3 times per minute (Row 2). These figures account for $100 \%$ of the verbalizations (Row 3 ) received by Subject 1 . The next two entries in the totals column are redundant in that they both show that the verbal activity directed to Subject 1 accounts for 30\% of all speaking in the group for this session. Interpreting the other figures in the final column is the same. The last five entries in the column show that a total of 100 verbalizations were recorded for this group, a rate of 10 per minute. This total accounts for $100 \%$ of all recorded verbal interactions.

The first analysis program provides the basic information upon which a number of other statistical manipulations can be performed. Within these descriptive summaries are all the data necessary to derive the relative frequencies of particular behaviors compared with all interactions. Data can be combined for the various observation sessions in any manner deemed important. When observing families, we combined sessions occurring just before a child went to camp, sessions taking place during the child's absence, and the observations taking place immediately after the child's return. In effect, naturally occurring events such as these are analogous to an ABA experimental design in which the approximations to a baseline/ intervention/return to baseline show the influence of changing environmental circumstances on social interaction.

\section{Observer Agreement}

Since two observers are present for most sessions, two rate matrices of the type described above are usually available for each session. Rate matrices are stored in NOS files that can be retrieved using system commands. NOS files are analyzed by using a special BASIC program that builds both a SPSS control statement file, from RUN NAME through FINISH, and a subset of the two rate files. Using SPSS linear regression programs, the rates of behavior derived from the first observer's records are paired with the equivalent rates for the second observer. The resulting output assesses the correlation, slope, and intercept between the rates reported by the two observers for each logical combination of behaviors possible with the code. The greater the positive correlation, the more confident we can be that our observers agree that they viewed the same activities. In general, agreement is greatest for verbal behavior, least for the affect codes. Agreement coefficients are printed at the terminal or at a central printer.

\section{Reciprocity}

While reciprocity (equality in behavior exchange) implies a contingent relationship between the behavior of two people or groups, the contingency does not necessarily demand an immediate response. For example, if a person is ill-treated by another on a given occasion, the opportunity to avenge the wrong may not occur until later.

Following this line of reasoning, analysis of reciprocity does not require contiguity between behaviors. Rather, we are interested in the degree to which rates of behavior between two actors tend to correlate over time (see Baum, 1973, for a discussion of correlation vs. contiguity). To achieve this end, the second analytic program analyzes the degree to which the behavior exchange between individuals is approximately equal in the long run. If the correlation and slope for behavior rates within dyads is approximately 1.0 and the intercept close to zero, then the exchange of behavior is reciprocal. Reciprocity measured in this way may be used as a dependent variable; that is, increases or decreases in reciprocity may be measured as a function of experimental manipulations.

\section{Equity 1 and 2}

The basic characteristic of equity is that the inputs of an actor are proportional to his outcomes (Adams, 1965; Homans, 1974). While two persons working on a task may receive unequal payoffs, the rewards may be equitable as long as the actor receiving the greater benefit has invested greater resources than the other. 
We are interested in the concept of equity as it applies to direct behavioral exchange. Referring to Table 4, the percentages in our descriptive matrices provide at least two ways to explore equity. With Equity 1, correlation coefficients and slopes are computed between the proportional exchanges of behavior in a dyad. Since one person may simply be more verbal than another, rates of verbal exchange may be unequal or only minimally reciprocal. However, if Subject 1 directs $50 \%$ of his verbalizations to Subject 2, who responds in kind, equity exists.

Equity 1 accounts for the notion that some people are highly active and others less so; it does not explore how alternatives for social interaction influence social exchange. For example, one person may interact with a large number of people, another with very few. In a sense, then, any behavior by the first actor is seemingly worth more since it is apparently desired by so many. For this individual, an equitable relationship may exist even when he responds to another at a lower rate of behavior than he receives. Equity 2 addresses this issue.

Equity 2 is similar to the matching law of behavior suggested by Herrnstein (1970) from experimentation with infrahumans and related to human social interaction by Homans (1974). The matching equation,

$$
\frac{B_{1}}{B_{1},+\ldots+, B_{n}}=\frac{R_{1}}{R_{1},+\ldots+, R_{n}}
$$

states that the occurrence of a behavior relative to some source of teinforcement is proportional to the payoff from that source. Approximations to matching have been demonstrated for human interaction in both experimental (Conger \& Killeen, 1974) and field settings (Conger, 1976). Simply stated, an individual should allocate a proportion of his behavior (e.g., verbalizations) to another person in an amount equal to the proportion of communications received.

Table 4 shows that Subject 1 directs approximately $33 \%$ of his verbal communications to Subject 2. In return, Subject 2 accounts for about $67 \%$ of all verbalizations received by Subject 1 . If, over time, this situation typified the group, it would be extremely inequitable. By using the data from our first descriptive program, we can use SPSS routines to compute the appropriate slopes, correlations, and intercepts in order to assess the degree to which Equity 2 actually characterizes the groups we observe, and to chart the influence of other factors on its maintenance or dissolution.

\section{Microscopic Analyses}

Currently, we are developing programs designed to discover the immediate effects that the behavior of one person has on the response of another. These microscopic contingencies fall into two categories: interacts and sequential dependencies.

Interacts. Since behaviors are recorded in sequence, these programs allow us to examine the manner in which distinct chains of interactions are formed. For example, in highly expressive groups where affect is largely positive, a verbal initiation by one group member may lead not only to a response by another but also to relatively extended verbal interaction within the dyad. Less positively expressive groups may show few such response chains. Such transactions can be viewed as interacts that vary in length from an initiation and response to initiation-response and any number of continuing responses.

By limiting the amount of time during which a given length interact can occur, we assess the responsiveness of group members to each other. For example, some types of families experiencing severe emotional problems may show relatively few initiation-response chains within a 6-sec period compared to controls.

Sequential dependencies. Patterson (1976) has made extensive use of conditional probabilities. As a result, he has found that parents with a particularly aggressive child are more likely to respond negatively and positively in reaction to such aggressiveness than matched controls.

Basically, unconditional probabilities are computed for each behavior type possible. These relative frequencies are easily obtained from our current descriptive information illustrated in Table 4. Then, the probability that a particular response will occur is computed, given that a specific behavior by another group member immediately precedes or follows the response. One may, for example, be interested in the probability of one person responding negatively to another, given that the latter has just behaved positively to the first. The conditional probability, when significantly lower or higher than the unconditional, suggests functional relationships between behaviors that may be explored further experimentally. The same approach can be used to explore similar relationships between behaviors when they are separated by other activities (Sackett, Note 2).

\section{COMMENTS}

We have described the qualities of the Datamyte 900 that have been especially useful. However, there are some drawbacks: (1) The unit is quite expensive. (Two Datamytes plus necessary accessories totaled slightly more than $\$ 5,000$.) (2) Memory loss is a potential problem when the unit is battery powered. Although the manufacturer suggests that fully charged batteries will maintain memory for $8 \mathrm{~h}$, there is no way within the unit to guarantee that batteries are fully charged before going into the field. Since power must remain on until coded data are transmitted elsewhere for 
permanent storage, a long delay between observing and data transmission may result in lost data.

By providing a stand-by battery, an audible signal which sounds if the battery is low, and a multifunction power/charger device, Electro/General Corporation has mitigated some of the problems that occur with any battery-powered event recorder. In numerous simulations of field observations with the Datamyte, we have lost memory only once. ${ }^{3}$ But any loss of information can be a serious problem, particularly when an experimental manipulation is taking place. Therefore, some quick method of estimating battery life before observing would be especially helpful. The current battery test procedure provided by the power/charger unit is too time consuming to meet this (usually daily) need. For those working in laboratories with ac current, this particular problem is irrelevant.

In spite of these deficiencies, the Datamyte 900 meets our needs quite well.

\section{REFERENCE NOTES}

1. Burgess, R. L.. \& Conger, R. D. Family interaction in abusive, neglectful, and normal families. Unpublished manuscript, 1977.

2. Sackett, G. P. A nonparametric lag sequential analysis for studying dependency among responses in observational scoring systems. Unpublished manuscript, University of Washington, Seattle, 1975.

\section{REFERENCES}

ADAms, J. S. Inequity in social exchange. In L. Berkowitz (Ed.), Advances in experimental social psychology (Vol. 2). New York: Academic Press, 1965. Pp. 267-299.

BARker, R. G. Ecological psychology. Stanford, Calif: Stanford University Press, 1968.

Baum, W. M. The correlation-based law of effect. Journal of the Experimental A nalysis of Behavior, 1973, 20, 137-153.

BLURTON-JoNes, N. B. (Ed.). Ethological studies of child behavior. London and New York: Cambridge University Press, 1972.

CONGER. R. D. A comparative study of interaction patterns between deviant and nondeviant families. Unpublished $\mathrm{PhD}$ dissertation, University of Washington, Seattle, 1976.

Conger, R. D., \& Killeen, P. Use of concurrent operants in small group research. Pacific Sociological Review, 1974, 17, 399-416.

HeRRNSTEIn, R. J. On the law of effect. Journal of the Experimental Analysis of Behavior, 1970, 13, 243-266.
Homans, G. C. Social behavior: Its elementary forms (Revised ed.). New York: Harcourt Brace Jovanovich, 1974.

Johnson, S. M., \& Bolstad, O. D. Methodological issues in naturalistic observation: Some problems and solutions for field research. In L. A. Hamerlynck, L. C. Handy, \& E. J. Mash (Eds.), Behavior change: Methodology, concepts and practice. Champaign, Ill: Research Press, 1973. Pp. 7-67.

Johnson, S. M., \& Lobitz, G. K. Parental manipulation of child behavior in home observations. Journal of Applied Behavior Analysis, 1974, 7, 23-31.

Johnson, S. M., Wahl, G., Martin, S., \& Johansson, S. How deviant is the normal child? A behavioral analysis of the preschool child and his family. In R. D. Rubin. J. P. Brady, \& J. D. Henderson (Eds.), Advances in behavior therapy (Vol. 4). New York: Academic Press, 1974. Pp. 37-54.

Patrerson, G. R. A basis for identifying stimuli which control behavior in natural settings. Child Development, 1974 , 45, 900-911.

Patterson, G. R. The aggressive child: Victim and architect of a coercive system. In E. J. Mash, L. A. Hamerlynck, \& L. C. Handy (Eds.), Behavior modification and families. New York: Brunner-Mazel, 1976. Pp. 267-316.

Torgerson, L. Datamyte 900. Behavior Research Methods \& Instrumentation, 1977, 9, 405-406.

\section{NOTES}

1. Complete definitions and illustrations for the various code categories may be obtained from the authors. The history of the code originates with work done at the Experimental Education Unit, the University of Washington, Seattle. There, a number of researchers, including Robert Burgess, John Gregory, Mike Meighan, and Dennis Mithaug, began using observational procedures developed at the University of Washington Primate Center to study human interaction. The form of the code presented here represents a natural evolution of that earlier work. It is impossible to separate the distinct contributions of those involved with the development of the code, but we must stress that our description by no means implies that we take credit for its existence.

2. The method for calculating behavior rates is based on opportunities for interaction. For dyads, one person can be coded interacting with another any time either is defined as the focal subject. Therefore, time as focal is summed for both members of a dyad and the frequency of responses by each person to the other is divided by this sum to determine the behavioral rate of interest. In Table 4, each person was assumed to be focal for $5 \mathrm{~min}$.

3. This problem is certainly not unique to the Datamyte. The first author has experienced similar problems with other event recorders where cassette tapes were used to store data. To date, the Datamyte has proven far more reliable.

(Received for publication July 5, 1977; revision accepted August 12, 1977.) 